\title{
Relationship between Body Condition Score and Postpartum Changes in Local Goats under Field Conditions
}

\author{
C. H. Venkata Reshma*, A. Anitha, S. Jagadeeswara Rao and M. Muralidhar \\ Department of Livestock Production Management, Nandamuri Taraka Ramarao College of \\ Veterinary Science, Gannavaram, India \\ *Corresponding author
}

\section{A B S T R A C T}

\section{Keyw ords \\ Body condition score, Postpartum changes, BCSK (BCS at kidding), LBCS (Loss in BCS), GBCS (Gain in $\mathrm{BCS}$ )}

Article Info

Accepted:

15 December 2020 Available Online: 10 January 2021
To assess the relationship between Body Condition Score (BCS) and postpartum changes of goats under field conditions, a study was conducted on goat flocks of farmers in and around Prakasam district. The postpartum changes studied in BCS of 60 does which were divided into three groups (Group I- 2.50-2.99, Group II- 3.00-3.49 and Group III- 3.503.99) based on BCS showed that the does were in the BCS range of $2.50-3.75$ at kidding. Does in the test flock were in the BCS range of $2.50-3.75$ at kidding, reduced their body condition during early lactation and so the minimum BCS of $2.00-2.99$ was recorded for majority of the does (55). The mean BCSK was 3.11 which was decreased to 2.87 at first week postpartum, further decreased to 2.42 by 12 weeks postpartum and later on increase gradually to 2.80 by 18 weeks postpartum. LBCS of the test flock ranged from 0.50 to 1.00 with a mean value of 0.70 . GBCS of the test flock ranged from 0.25 to 0.50 with a mean value of 0.38. Minimum BCS of the test flock ranged from 2.00 to 3.00 with a mean value of 2.41. A significant $(\mathrm{P}<0.01)$ difference was observed between the does of different groups of BCSK in LBCS, GBCS and minimum BCS. The mean BCS was decreased from first week to 10 weeks postpartum for the does of BCSK 2.50 to 2.99 , from first week to 11 weeks postpartum for the does of BCSK 3.00 to 3.49 and from first week to 12 weeks for the does of BCSK 3.50 to 4.00, thereafter showed an increased trend for the does of three BCSK groups. The highest loss as well as gain in BCS was achieved by the BCSK group 3.50 to 4.00 compared to the BCSK group 2.50 to 2.99 and 3.00 to 3.49.

\section{Introduction}

Body condition is a term used to indicate the body reserves present in an individual animal. An animal's body condition indicates the amount of lipid (fat) and protein (muscle) reserves that are available for maintenance, gestation and production. Body Condition Scoring is an important tool for livestock managers to optimize the production, feeding program and welfare of the animals they manage (Carlson, 2017). Body condition score (BCS) has been shown to be an important practical tool in assessing the body condition of goats because BCS is the best simple indicator of available fat reserves which can be used by the animal in periods of high energy demand, stress, or suboptimal 
nutrition (Villaquiran et al., 2007). There is a need to evaluate the fitness of goat using body condition scoring and suggest the farmers regarding the BCS to be maintained for optimum productivity of their' goat flocks. Thus a study was undertaken to assess the utility of BCS for the assessment of reproductive performance.

\section{Materials and Methods}

The study was carried out on 6 goat flocks of farmers in and around Prakasam district. A total of 60 late gestation does were selected that are maintained under semi - intensive production system and fed daily with concentrate mixture @ 300g per head in addition to grazing. The does were divided into three groups (Group I- 2.50-2.99, Group II- 3.00-3.49 and Group III- 3.50-3.99) based on BCS. A BCS scale of 1 to 5 (Carlson, 2017) was used to score the does. This method considers the muscle and fat over shoulder region, ribs, spinous and transverse processes of lumbar vertebrae and hip bones. A score of ' 1 ' is considered as emaciated condition and a score of ' 5 ' considered as obese condition. Scoring was done by using the hand to feel for the fullness of muscling and fat cover over and around the vertebrae in the loin region.

\section{Results and Discussion}

The frequency tabulation of BCSK and minimum BCS of test flock of 60 does showed that out of 60 does used for postpartum changes in BCS, more number of does were in the BCS range of $2.50-2.74$ at kidding followed by BCSK range of 3.25 $3.49,3.50-3.74,3.75-3.99,3.00-3.24$ and $2.75-2.99$. There were no does in either poor (below 2.00) or obese (5.00) body condition at kidding (Table 1). It showed that the does in gestation and near to parturition were maintained on good plane of nutrition resulted in ideal BCSK. Out of 60 does tested for the postpartum changes by recording minimum BCS values during early lactation of the test period of 18 weeks, more number of ewes had the minimum BCS of $2.00-2.24$ (17) followed by $2.75-2.99$ (14). Does in the test flock were in the BCS range of $2.50-3.75$ at kidding, have reduced their body condition during early lactation as the fat reserves were mobilized for milk production and so the minimum BCS of $2.00-2.99$ was recorded for majority of the does (55).

The BCS values assigned to the does 2 weeks before kidding, one week before kidding, BCSK and weekly postpartum changes up to 18 weeks of all the does in the test flock showed that there was no loss in mean BCS of does of test flock from 2 weeks before kidding to BCSK. There was a loss in mean BCS of 0.24 unit from BCSK to the first week postpartum. The mean postpartum losses ranged from 0.24 to 0.69 . It was similar to the findings of Anusha (2016) who reported that there was no loss in mean BCS of ewes from 2 weeks before kidding to BCSL, there was a loss in mean BCS of 0.24 unit from BCSK to the first week postpartum and the mean postpartum losses ranged from 0.24 to 0.77 . However, these losses were found to be recouped during the remaining postpartum study period of 18 weeks as the does showed improvement in body condition. The loss in BCS during first 12 weeks after kidding is mainly because of mobilization of body fat reserves for milk production. The regain in the BCS after 12 weeks was mainly due to replenishing of body fat reserves by the does after weaning of kids. Based on the results at 18 weeks postpartum it can be predicted that does might have regained the normal BCS.

The BCSK, LBCS, GBCS and minimum BCS of the test flock presented in Table 2 showed that the mean BCSK of test flock was 3.11. The mean LBCS was 0.70 and mean GBCS 
was 0.38 . The results showed that the mean LBCS was higher by 0.32 units than mean GBCS over 18 weeks postpartum. However, the does might have regained LBCS in the subsequent weeks which was proved by GBCS of 0.38 within 6 weeks from 13 weeks postpartum. The mean value of minimum
BCS over the period of 18 weeks postpartum was 2.41. The results showed that though there was loss in body fat reserves due to milk production the does could maintain a mean minimum BCS value of 2.41. This indicated that the does have not gone down to poor body condition of below 2.00 .

Table.1 Frequency tabulation of BCSK and minimum BCS of test flock $(n=60)$

\begin{tabular}{|c|c|c|c|c|c|c|}
\hline \multirow{2}{*}{ BCS } & \multicolumn{2}{|c|}{ Frequency } & \multicolumn{2}{c|}{ Relative frequency } & \multicolumn{2}{c|}{ Cumulative frequency } \\
\cline { 2 - 7 } & BCSK & Minimum BCS & BCSK & Minimum BCS & BCSK & Minimum BCS \\
\hline $\mathbf{1 . 0 0 - 1 . 2 4}$ & 0 & 0 & 0 & 0 & 0 & 0 \\
\hline $\mathbf{1 . 2 5 - 1 . 4 9}$ & 0 & 0 & 0 & 0 & 0 & 0 \\
\hline $\mathbf{1 . 5 0 - 1 . 7 4}$ & 0 & 0 & 0 & 0 & 0 & 0 \\
\hline $\mathbf{1 . 7 5 - 1 . 9 9}$ & 0 & 0 & 0 & 0 & 0 & 0 \\
\hline $\mathbf{2 . 0 0 - 2 . 2 4}$ & 0 & 17 & 0 & 0.28 & 0 & 0.28 \\
\hline $\mathbf{2 . 2 5 - 2 . 4 9}$ & 0 & 11 & 0 & 0.18 & 0 & 0.46 \\
\hline $\mathbf{2 . 5 0 - 2 . 7 4}$ & 14 & 13 & 0.23 & 0.21 & 0.23 & 0.68 \\
\hline $\mathbf{2 . 7 5 - 2 . 9 9}$ & 06 & 14 & 0.10 & 0.23 & 0.33 & 0.91 \\
\hline $\mathbf{3 . 0 0 - 3 . 2 4}$ & 08 & 05 & 0.13 & 0.08 & 0.46 & 1 \\
\hline $\mathbf{3 . 2 5 - 3 . 4 9}$ & 12 & 0 & 0.20 & 0 & 0.66 & 1 \\
\hline $\mathbf{3 . 5 0 - 3 . 7 4}$ & 11 & 0 & 0.18 & 0 & 0.85 & 1 \\
\hline $\mathbf{3 . 7 5 - 3 . 9 9}$ & 09 & 0 & 0.15 & 0 & 1 & 1 \\
\hline $\mathbf{4 . 0 0 - 4 . 2 4}$ & 0 & 0 & 0 & 0 & 1 & 1 \\
\hline $\mathbf{4 . 2 5 - 4 . 4 9}$ & 0 & 0 & 0 & 0 & 1 & 1 \\
\hline $\mathbf{4 . 5 0 - 4 . 7 4}$ & 0 & 0 & 0 & 0 & 1 & 1 \\
\hline $\mathbf{4 . 7 5 - 5 . 0 0}$ & 0 & 0 & 0 & 0 & 1 & 1 \\
\hline
\end{tabular}

Table.2 BCSK, LBCS, GBCS and minimum BCS of the test flock $(n=60)$

\begin{tabular}{|c|c|c|c|c|}
\hline S.No & BCSK & LBCS & GBCS & Minimum BCS \\
\hline $\mathbf{1}$ & 2.50 & 0.50 & 0.25 & 2.00 \\
\hline $\mathbf{2}$ & 2.75 & 0.50 & 0.25 & 2.25 \\
\hline $\mathbf{3}$ & 2.50 & 0.50 & 0.25 & 2.00 \\
\hline $\mathbf{4}$ & 3.00 & 0.75 & 0.25 & 2.25 \\
\hline $\mathbf{5}$ & 3.25 & 0.75 & 0.50 & 2.50 \\
\hline $\mathbf{6}$ & 3.75 & 0.75 & 0.50 & 3.00 \\
\hline $\mathbf{7}$ & 3.50 & 0.75 & 0.50 & 2.75 \\
\hline $\mathbf{8}$ & 2.50 & 0.50 & 0.25 & 2.00 \\
\hline $\mathbf{9}$ & 3.25 & 0.75 & 0.50 & 2.50 \\
\hline $\mathbf{1 0}$ & 3.50 & 0.75 & 0.50 & 2.75 \\
\hline $\mathbf{1 1}$ & 2.75 & 0.75 & 0.25 & 2.00 \\
\hline $\mathbf{1 2}$ & 3.00 & 0.75 & 0.50 & 2.25 \\
\hline $\mathbf{1 3}$ & 3.25 & 0.75 & 0.50 & 2.50 \\
\hline $\mathbf{1 4}$ & 3.75 & 1.00 & 0.50 & 2.75 \\
\hline
\end{tabular}




\begin{tabular}{|c|c|c|c|c|}
\hline 15 & 3.50 & 0.75 & 0.50 & 2.75 \\
\hline 16 & 2.50 & 0.50 & 0.25 & 2.00 \\
\hline 17 & 2.75 & 0.50 & 0.25 & 2.25 \\
\hline 18 & 3.00 & 0.75 & 0.50 & 2.25 \\
\hline 19 & 3.25 & 0.75 & 0.25 & 2.50 \\
\hline 20 & 3.00 & 0.75 & 0.50 & 2.25 \\
\hline 21 & 3.50 & 0.75 & 0.50 & 2.75 \\
\hline 22 & 3.75 & 0.75 & 0.50 & 3.00 \\
\hline 23 & 3.75 & 1.00 & 0.50 & 2.75 \\
\hline 24 & 3.50 & 0.75 & 0.25 & 2.75 \\
\hline 25 & 3.25 & 0.75 & 0.25 & 2.50 \\
\hline 26 & 3.00 & 0.75 & 0.25 & 2.25 \\
\hline 27 & 3.00 & 0.75 & 0.25 & 2.25 \\
\hline 28 & 2.50 & 0.50 & 0.25 & 2.00 \\
\hline 29 & 2.50 & 0.50 & 0.25 & 2.00 \\
\hline 30 & 2.75 & 0.75 & 0.25 & 2.00 \\
\hline 31 & 3.00 & 0.75 & 0.25 & 2.25 \\
\hline 32 & 3.25 & 0.75 & 0.50 & 2.50 \\
\hline 33 & 2.75 & 0.75 & 0.50 & 2.00 \\
\hline 34 & 3.50 & 1.00 & 0.50 & 2.50 \\
\hline 35 & 3.50 & 0.75 & 0.50 & 2.75 \\
\hline 36 & 3.75 & 0.75 & 0.50 & 3.00 \\
\hline 37 & 3.75 & 0.75 & 0.50 & 3.00 \\
\hline 38 & 2.50 & 0.50 & 0.25 & 2.00 \\
\hline 39 & 2.50 & 0.50 & 0.25 & 2.00 \\
\hline 40 & 2.75 & 0.50 & 0.25 & 2.25 \\
\hline 41 & 3.25 & 0.75 & 0.50 & 2.50 \\
\hline 42 & 3.25 & 0.75 & 0.50 & 2.50 \\
\hline 43 & 2.50 & 0.50 & 0.25 & 2.00 \\
\hline 44 & 3.50 & 0.75 & 0.50 & 2.75 \\
\hline 45 & 3.75 & 1.00 & 0.25 & 2.75 \\
\hline 46 & 3.25 & 0.75 & 0.50 & 2.50 \\
\hline 47 & 2.50 & 0.50 & 0.25 & 2.00 \\
\hline 48 & 2.50 & 0.50 & 0.25 & 2.00 \\
\hline 49 & 3.25 & 0.75 & 0.50 & 2.50 \\
\hline 50 & 3.50 & 0.75 & 0.50 & 2.75 \\
\hline 51 & 2.50 & 0.50 & 0.25 & 2.00 \\
\hline 52 & 3.75 & 0.75 & 0.50 & 3.00 \\
\hline 53 & 3.25 & 0.75 & 0.50 & 2.50 \\
\hline 54 & 3.50 & 0.75 & 0.50 & 2.75 \\
\hline 55 & 3.75 & 1.00 & 0.50 & 2.75 \\
\hline 56 & 3.50 & 0.75 & 0.50 & 2.75 \\
\hline 57 & 2.50 & 0.50 & 0.25 & 2.00 \\
\hline 58 & 2.50 & 0.50 & 0.25 & 2.00 \\
\hline 59 & 3.25 & 0.75 & 0.25 & 2.50 \\
\hline 60 & 3.00 & 0.75 & 0.50 & 2.25 \\
\hline Mean & 3.11 & 0.70 & 0.38 & 2.41 \\
\hline
\end{tabular}


Table.3 LBCS, GBCS and minimum BCS of does of different groups of BCSK in the test flock

\begin{tabular}{|c|c|c|c|c|c|c|c|c|}
\hline \multirow{2}{*}{ Groups } & \multicolumn{2}{|c|}{ BCSK } & \multicolumn{2}{c|}{ LBCS } & \multicolumn{2}{c|}{ GBCS } & \multicolumn{2}{c|}{ Minimum BCS } \\
\cline { 2 - 9 } & Mean & SE & Mean & SE & Mean & SE & Mean & SE \\
\hline $\begin{array}{c}\mathbf{2 . 5 0}- \\
\mathbf{2 . 9 9}\end{array}$ & $2.57^{\mathrm{c}}$ & 0.02 & $0.53^{\mathrm{c}}$ & 0.02 & $0.26^{\mathrm{c}}$ & 0.01 & $2.03^{\mathrm{c}}$ & 0.02 \\
\hline $\begin{array}{c}\mathbf{3 . 0 0}- \\
\mathbf{3 . 4 9}\end{array}$ & $3.15^{\mathrm{b}}$ & 0.02 & $0.75^{\mathrm{b}}$ & 0.00 & $0.41^{\mathrm{b}}$ & 0.02 & $2.40^{\mathrm{b}}$ & 0.02 \\
\hline $\begin{array}{c}\mathbf{3 . 5 0}- \\
\mathbf{4 . 0 0}\end{array}$ & $3.61^{\mathrm{a}}$ & 0.02 & $0.81^{\mathrm{a}}$ & 0.02 & $0.47^{\mathrm{a}}$ & 0.01 & $2.80^{\mathrm{a}}$ & 0.02 \\
\hline Overall & 3.11 & 0.05 & 0.70 & 0.01 & 0.38 & 0.01 & 2.41 & 0.04 \\
\hline
\end{tabular}

Means with different superscripts column wise under each category differ significantly $(\mathrm{P}<0.01)$

Table.4 ANOVA for BCSK, LBCS, GBCS and minimum BCS of different groups of BCSK in the test flock

\begin{tabular}{|c|c|c|c|c|c|}
\hline & Source & df & SS & MSS & F- ratio \\
\hline \multirow[t]{2}{*}{ BCSK } & $\begin{array}{l}\text { Between } \\
\text { Groups }\end{array}$ & 2 & 10.80 & 5.40 & \multirow[t]{2}{*}{$353.24 * *$} \\
\hline & Within Groups & 57 & 0.87 & 0.02 & \\
\hline \multirow[t]{2}{*}{ LBCS } & $\begin{array}{c}\text { Between } \\
\text { Groups }\end{array}$ & 2 & 0.83 & 0.42 & \multirow[t]{2}{*}{$60.17 * *$} \\
\hline & Within Groups & 57 & 0.39 & 0.01 & \\
\hline \multirow[t]{2}{*}{ GBCS } & $\begin{array}{l}\text { Between } \\
\text { Groups }\end{array}$ & 2 & 0.47 & 0.24 & \multirow[t]{2}{*}{$29.80 * *$} \\
\hline & Within Groups & 57 & 0.45 & 0.01 & \\
\hline \multirow[t]{2}{*}{$\begin{array}{l}\text { Minimum } \\
\text { BCS }\end{array}$} & $\begin{array}{l}\text { Between } \\
\text { Groups }\end{array}$ & 2 & 5.81 & 2.91 & \multirow[t]{2}{*}{$211.42 * *$} \\
\hline & Within Groups & 57 & 0.78 & 0.01 & \\
\hline
\end{tabular}

** Significant $(\mathrm{P}<0.01)$

The values of BCSK and weekly postpartum changes of BCSK group $2.50-2.99$ showed that the mean BCS value remained same from 2 week before kidding to BCSK. There was a loss in mean BCS of 0.25 unit from BCSK to the first week postpartum and loss in BCS was continued up to 10 weeks postpartum. The mean postpartum losses ranged from 0.25 to 0.54. However, during the remaining postpartum study period of 18 weeks the does showed improvement in body condition.

The values of BCSK and weekly postpartum changes of BCSK group 3.00 - 3.49 revealed that there was no loss in mean BCS of does from 2 weeks before kidding to BCSK. There was a loss in mean BCS of 0.23 unit from BCSK to first week postpartum and loss in BCS was continued up to 11 weeks postpartum. The mean postpartum losses ranged from $0.23-0.75$. However, these losses were found to be recouped during the remaining postpartum study period of 18 weeks as the does showed improvement in body condition. The values of BCSK and weekly postpartum changes of BCSK group $3.50-4.00$ showed that there was no loss in mean BCS of does from 2 weeks before kidding to BCSK. There was a loss in mean BCS of 0.25 unit from BCSL to first week 
postpartum and loss in BCS was continued up to 12 weeks postpartum. The mean postpartum losses ranged from $0.25-0.80$. However, these losses were found to be recouped during the remaining postpartum study period of 18 weeks as the does showed improvement in body condition. This indicated that does with higher BCSK lost more BCS and it was also observed that they have reached minimum BCS one week later than the does with BCSK $2.50-2.99$. This was in agreement with the general consensus, that the does with excessive fat at kidding lose excessive body reserves as the fat reserves could be mobilized too rapidly.

The LBCS, GBCS and minimum BCS of different groups of BCSK in the test flock presented in Table 3 and 4 revealed that the does of BCSK group 3.50- 4.00 had significantly $(\mathrm{P}<0.01)$ more LBCS followed by BCSK group $3.00-3.49$ and $2.50-2.99$. Does of BCSK group 3.50 - 4.00 showed higher gain in BCS (0.47) followed by BCSK group 3.00 - 3.49 (0.41) and BCSK group $2.50-2.99(0.28)$. The results indicated that the magnitude of body condition loss and gain depended on BCSK. Does with BCSK of 2.50 -2.99 and $3.00-3.49$ have gone down to a mean minimum BCS of 2.03 and 2.40, respectively during lactation whereas does with BCSK of $3.50-4.00$ could maintain a significantly $(\mathrm{P}<0.01)$ higher minimum BCS of 2.80 and also showed more gain in BCS subsequently. The results revealed that does with BCSK of $2.50-2.99$ have gone down to a minimum BCS of 2.03 indicating thin body condition which may result in negative energy balance leading to metabolic disorders and also reduced performance in future. It was similar to the findings of Freer et al., (2007).

In conclusion the present study suggested an optimum BCS of $3.50-4.00$ at kidding so that the does could maintain the optimum body condition during lactation as well as replenish the body fat reserves by regaining BCS more efficiently.

\section{Acknowledgments}

It is an immense pleasure to express my deep sense of thanks and gratitude to my guide Dr.A.Anitha. I would like to express my profound gratitude to my committee members Dr. S. Jagadeeswara Rao, Dr. M. Muralidhar and to Dr. K. Sudhakar.. I owe to acknowledge Dr.Ch. Venakta Seshaiah, Professor, Department of LFC, NTR College of Veterinary Science, Gannavaram and Dr. Kalyana Chakravarthy, Assistant Professor, Department of LFC, N T R College of Veterinary Science, Gannavaram, for their kind advices and timely guidance during the period of investigation.

\section{References}

Anusha V. (2016). Utility of body condition score (BCS) system for the assessment of physical traits and performance of Nellore (Brown) sheep. Thesis submitted to Sri Venkateswara Veterinary University, Tirupati pp: 59 76.

Carlson, J. (2017). Dairy goat body condition scoring. American Dairy Goat Association and University of California, Davis, Department of Animal Science and School of Veterinary Medicine. http:// adga.org/wp-content/ adga-dairy-goatbody.

Freer M, Dive H and Nolan JV. (2007). Nutrient requirements of domesticated ruminants. Collingwood, CSIRO Publishing pp: 50-61.66

Villaquiran, M., Gipson, T.A., Merkel, R.C., Goetsch, A and Sahlu, T. (2007). Body Condition Scores in Goats. Proc. 22nd Ann. Goat Field Day, Langston University, Langston: 125-131. 


\section{How to cite this article:}

Venkata Reshma, C. H., A. Anitha, S. Jagadeeswara Rao and Muralidhar, M. 2021. Relationship between Body Condition Score and Postpartum Changes in Local Goats under Field Conditions. Int.J.Curr.Microbiol.App.Sci. 10(01): 2639-2645.

doi: https://doi.org/10.20546/ijcmas.2021.1001.307 